\title{
The mediating role of Social Loafing and job insecurity in the effect of organizational forgetfulness on organizational commitment in government organizations
}

\author{
Shokoufeh Zare, Ehsan Bakhshandeh \\ Department of Management, Islamic Azad University, Larestan Branch, Larestan, Iran.
}

\begin{abstract}
This study was conducted to investigate the mediating role of Social Loafing and job insecurity in the impact of organizational forgetting on organizational commitment in government agencies. For this purpose, for measuring organizational forgetfulness, a questionnaire by Aledo Ruíz et al. (2013), for measuring job insecurity, a questionnaire by Ouyang et al. (2015), for measuring social embarrassment of employees, using a questionnaire by Karadal \& Saygin (2013), and for measuring organizational commitment. The standard questionnaire of Allen \& Meyer (1990) was used and the research questionnaire was distributed among 375 sample of the statistical population, which are all managers and employees of governmental organizations of Fars province. The research method was descriptive correlational. Structural equation analysis and partial least squares (PLS) method were used to answer the research questions and research hypotheses using Smart-PLS software. The results show that organizational forgetting has a significant and negative effect on job insecurity and Social Loafing. The results also show that job insecurity has a positive and significant effect on Social Loafing. Results of Social Loafing on Organizational Commitment and Impact of Organizational Forgetting on Organizational Commitment with regard to Mediation's Role Mediation, but Does Not Confirm the Impact of Job Insecurity on Organizational Commitment, and Effect of Forgetting on Organizational Commitment with Mediating Role of Job Insecurity.
\end{abstract}

Keywords: organizational forgetfulness, job insecurity, Social Loafing, organizational commitment 


\section{1- Introduction}

Forgetfulness is a process that occurs when people need to update scientific structures (such as laws, processes, or obligations) that have become obsolete over time (Aledo Ruíz et al., 2017). This is similar to what happens to some people when they buy a new coat and need to make room for it inside their jacket. When this happens, getting rid of unwanted clothes can be the first step. Although each person can forget differently, researchers have stated that forgetfulness can be accomplished through three different processes: (1) Awareness is the process by which some people become aware of outdated laws, procedures, or processes. . This can be done by identifying the person's personal mistakes or errors; (2) Leaving allows people to avoid repeating old mistakes, especially when they happen unintentionally; (3) Re-learning involves the ability to learn new things, when a person is doing something new, in fact, he is forgetting and putting something new next to the old thing (Becker, 2010; Cegarra et al., 2014)

The results of many studies on the role and importance of human resources in the growth and development of organizations and sometimes the growth of human societies focus on the fact that no society is developed unless it has developed its human resources. Today, human resources researchers have realized that skilled and skilled manpower are valuable agents and endless capital for the growth and development of organizations and countries (Blaga \& Jozsef, 2014).

One of the indicators of superiority of one organization over another is the existence of loyal and committed human resources. Understanding the status of organizational commitment of employees can help managers in the development and improvement of employees. Thirty years ago, there was considerable interest in understanding the concept of organizational commitment, and a great deal of effort was expended in analyzing this issue. The results of this research (Angel and Perry, 1981; Allen and Meyer, 1990, 1996, 2000; MacIntosh, E.W, \& Doherty, 2010; Jones \& McIntosh, 2010) suggest that organizational commitment to many behaviors Employee job is related. Researchers consider organizational commitment as an important variable in understanding employee behavior. Accordingly, organizational commitment has potentially serious effects on the performance of the organization, and therefore ignoring it is detrimental to the organization and leads to high costs.

An important and effective factor on organizational commitment can be social idleness. Unfortunately, the issue of social inequality is now seen in many government departments. Some office workers, despite having the ability to work and have enough time to do the client's affairs, refuse to do the relevant work and procrastinate the work that they have to do in a short time. Sometimes it is observed in an office that some employees do not show up for work under unreasonable excuses. Some employees at work are busy talking, reading the newspaper, or eating breakfast instead of doing office work.

Social idleness is a phenomenon in which group members reduce individual motivation and tend to work less when working collectively than when working individually (Ulke \& Bilgic, 2011). It is clear that different skills and perspectives come together in working groups and there is widespread synergy for the organization, although different types of teamwork have their negative effects. This situation can be the result of the concepts of social vanity.

Job insecurity is also a specific factor that affects organizational commitment (Ouyang et al., 2015). Job insecurity refers to employees' concerns about losing their job or job-related characteristics (Greenhalgh \& Rosenblatt, 1984). To create job insecurity in these texts, a distinction can be made between general and multidimensional definitions (Loi et al., 2012), general scales dealt with the permanent existence of jobs in the future, and multidimensional scales typically include factors such as threats to Multiple job characteristics, inability to deal with such threats, include the possibility of future employment (Cheng et al., 2011).

One of the skills that can help employees meet global challenges is "organizational forgetfulness". As talents, skills, or experiences accumulate over the years, members of the organization become very arrogant and complacent about what they know is difficult to learn new (Aledo Ruíz et al., 2017). 
However, in order to survive in today's increasingly chaotic work environment, organizations need to forget old knowledge or old rules and prevent it to create a path to new knowledge (Tsang \& Zahra, 2008). This study claims that creating an environment of organizational forgetfulness is necessary to develop and extract the capabilities and knowledge of employees and thus improve organizational performance. Previous studies have provided sufficient evidence to support individual factors such as organizational forgetfulness, job insecurity, and social idleness that significantly affect organizational commitment. However, few studies have examined how individual factors affect organizational commitment simultaneously. Therefore, considering the importance of this issue, the present study seeks to examine the question that what effect does organizational forgetfulness with the mediating role of job insecurity and social idleness have on organizational commitment?

\section{2- Theoretical foundations}

\section{2-1- Organizational forgetfulness}

The problem with forgetfulness is that you cannot measure it (Howells \& Scholderer, 2015). One of the rules of management is that if you can not measure it, you can not do it. The best way to solve this problem is through an area of organizational forgetfulness. As Azmi (2008) points out, forgetfulness can manifest itself in the organizational structure and through the creation and maintenance of a culture in which individuals consciously acquire new skills and knowledge at the same time, because they too They create time and opportunity to explore and extract current knowledge and new knowledge.

Forgetting enables the organization to identify mistakes, errors, or minor facts that may need to be discarded or ignored. For example, when managers learn from their personal mistakes and correct their decision patterns, they are ignoring their wrong or old patterns (Zhao et al., 2013). Researchers argue that "replacing old knowledge can be essential for organizations looking to create new products or services that need new perspectives and ideas." (Wang et al., 2013). Thus, organizational forgetfulness helps to prepare the necessary work environment to acquire and produce new knowledge

According to Cepeda et al. (2015), using organizational forgetfulness, organizations enable individuals to align their thinking patterns and the nature of common interests in order to avoid the new workplace culture. Since old and inadequate knowledge can prevent the application of new conditions, managers must create a continuous field of forgetfulness. In this way, employees can forget obsolete knowledge and are able to develop and re-learn updated knowledge. Employees must therefore have the ability to forget in order to learn new things, which is the key to real learning that manifests itself in reviewing and eliminating old habits and practices that are no longer appropriate for the company (Durst \& Edvardsson, 2012).

Organizational learning is divided into three stages: acquisition, distribution and application of knowledge. Acquiring knowledge requires constant efforts and continuous reviews by all employees of the organization. When a worker acquires knowledge, the company has to spread the knowledge among other members of the organization. This distribution involves the transfer of knowledge gained at an individual level, primarily through conversations, conversations, and personal relationships among the organization's employees that are encouraged by managers. Finally, in the knowledge utilization phase, individuals integrate aspects of knowledge that are not common to them through shared understanding and coordinated decision-making. Not only is gaining knowledge important, but the organization must have up-to-date discussions and processes in order to forget outdated habits and practices (Aledo Ruíz et al., 2017).

Based on the above ideas, organizations should use different strategies to remove outdated knowledge and build new organizational knowledge by utilizing the knowledge of employees. Scientific sources 
related to organizational learning state that organizational knowledge originates from an individual level (Birasnav, 2014). Individuals must therefore consider internal processes such as reflection, direct perception, or interpretation that are needed to satisfy workers if organizations are to seek the desirable exchange of views and ideas that facilitate the creation and emergence of human capital (Fornell, 2000). As a result, organizational forgetfulness contributes by preparing the ground for updating knowledge and scientific structures (Wensley \& Cegarra, 2015).

\section{2-2- Occupational insecurity}

The need for job security has been introduced as one of the basic needs of employees, which in normal circumstances, without providing it, it will not be possible to reach higher levels of human needs. Job security is a set of feelings and perceptions related to having a good job and ensuring its continuity in the future, as well as feeling or perceiving the threatening factors in that job. Increased conflict between employees and managers, the impossibility of planning a person for the future (professional / personal), the lack of peace of mind, negative physical and psychological effects of constant stress on the person, etc. can be negative consequences. Attention to the need for job security (Chang et al., 2017).

There are several definitions of job security, some of which are listed below:

-The feeling of job security is the feeling of relative relief from the danger or state in which the satisfaction of specific needs and desires is realized (Lu et al., 2019).

-The feeling of security requires the ability to maintain what a person has and is the product of ensuring the ability to make a living in the future.

Job security is the right to continue employment, which usually lasts until retirement

Using the above definitions, the following definition is provided as a complete definition:

The feeling of job security is a state that the result of the evaluation of the person leads him to the conclusion that a certain factor does not threaten his job security and he can be confident in the continuation of his employment now and in the future (Artz \& Kaya, 2015).

From what has been said, it follows that the feeling of job security is a mental phenomenon, that is, it is the feeling and perception of a person that creates job security or insecurity for him. Marks. Sometimes there may be no threatening factors in the workplace but the person feels threatened, or there may be threatening factors but the person does not feel threatened. In their research, Cobb and Kassel concluded that those who anticipate losing their job, or in other words, feel that they will lose their job, are more likely to lose their job than when they actually lose it. There is more stress (Burke, 1991).

In his theory, Lazaus emphasizes that regardless of the severity of the risk, the occurrence of stress depends on the individual's assessment of how threatening the situation is. Furthermore, the observer's attitude determines whether events are stressful, not the situation itself (Roskies \& Louis, 1990).

\section{2-3- Social Loafing}

Social Loafing is a phenomenon in which group members reduce individual motivation and tend to work less when working collectively than when working individually (Uike, 2011). Social Loafing has been identified as a highly validated cause of reduced productivity (George, 1992). Social idleness is 
based on disenfranchisement as a result of teamwork over individual activity.

As stated by Leiden et al. (2004) in their research, research on social vanity has been examined in theories of motivation and many precedents have been identified in this regard. Although there are many antecedents, the term social vanity has a motivational background. Potential antecedents of social void include:

-Lack of identification of individual collaborations with the group

- Lack of challenge and unity of individual cooperation

-Poor mental and internal conflict

-Desire for independence

•Poor group cohesion

-Lack of accurate evaluation (Maden, 2012)

Background The issue of social inequality contains empirical and theoretical evidence that provides insight into the nature and possible causes of social inequality. As a result, the tendency to social void is affected by a large number of variables and conditions that reduce or increase the likelihood of social void. These factors include (Yuki, 2006):

1. Group size

2. Difficulty of work

3. Recognizability of individual performance (clarity of tasks)

4. Concealed assessments with reasonable standards

5. Unnecessary work

6. Group performance expectations

7. Value of results

8. Individual involvement (meaningful tasks and work value)

9. Group cohesion and individual differences

\section{2-4- Organizational commitment}

Commitment has been defined by different people in different ways, some of which are examined below: Master Shahid Motahhari considers commitment to mean adherence to the principles and contracts that man believes in and states: "A committed person is one who To be faithful to one's covenant and to strive for its goals, "Kanter considers commitment as the desire of individuals to devote their energy and loyalty to the social system. Salankik sees commitment as linking a person to his or her individual factors and actions, that is, commitment becomes real when one feels responsible and dependent on one's behavior and actions (Cho \& Huang, 2012). 
Modi et al. Refer commitment to action beyond the statutory duties. Practical commitment is essential to getting things done, and it is especially important in key and sensitive jobs. Cook and Wall have also introduced the three concepts of "loyalty", "sense of identity and recognition" and "readiness" for commitment (Cullinan et al., 2008).

Organizational commitment is an attitude. It is a mental state that indicates a desire, need and obligation to continue working in an organization. Desire means the desire and heart desire of a person to continue serving in the organization, need means the person is forced to continue serving in the organization because of the investments he has made, and obligation is the religion, responsibility and duty that a person has towards the organization and obliges himself. He sees staying in it from another perspective, organizational commitment is a kind of sense of belonging and belonging to the organization (Westover et al., 2010).

Lack of sense of belonging to the organization and lack of accuracy to perform tasks is one of the major problems of the executive apparatus. Leaving service, absenteeism, delays, non-participation and active involvement of the labor force and low level of human resource performance are the most obvious examples of these problems that create a gap between human resources and organizations to solve this problem. Promoting commitment is one of the best ways (Cho \& Huang, 2012).

Organizational commitment, like other concepts in the field of humanities, has been given many definitions. Perhaps the reason for this is the introduction of "organizational commitment" in various fields and that experts in various fields in accordance with the use of this concept in They have discussed their topics and given definitions for it.

One of the most common ways to deal with organizational commitment is to consider organizational commitment as a kind of emotional and psychological dependence on the organization. According to this method, a person who is strongly committed to his organization; It derives its identity from the organization, actively participates in the organization, blends in with it, and enjoys membership in its organization (Westover et al., 2010).

\section{2-5- Conceptual model of research}

Considering that the purpose of this study is to investigate the mediating role of social idleness and job insecurity in the effect of organizational forgetfulness on organizational commitment in government organizations, therefore, the general framework of this study is to systematically explain the above issue in a systematic and principled manner. To test the hypotheses of this research, the conceptual model shown in Figure 1 is used. 


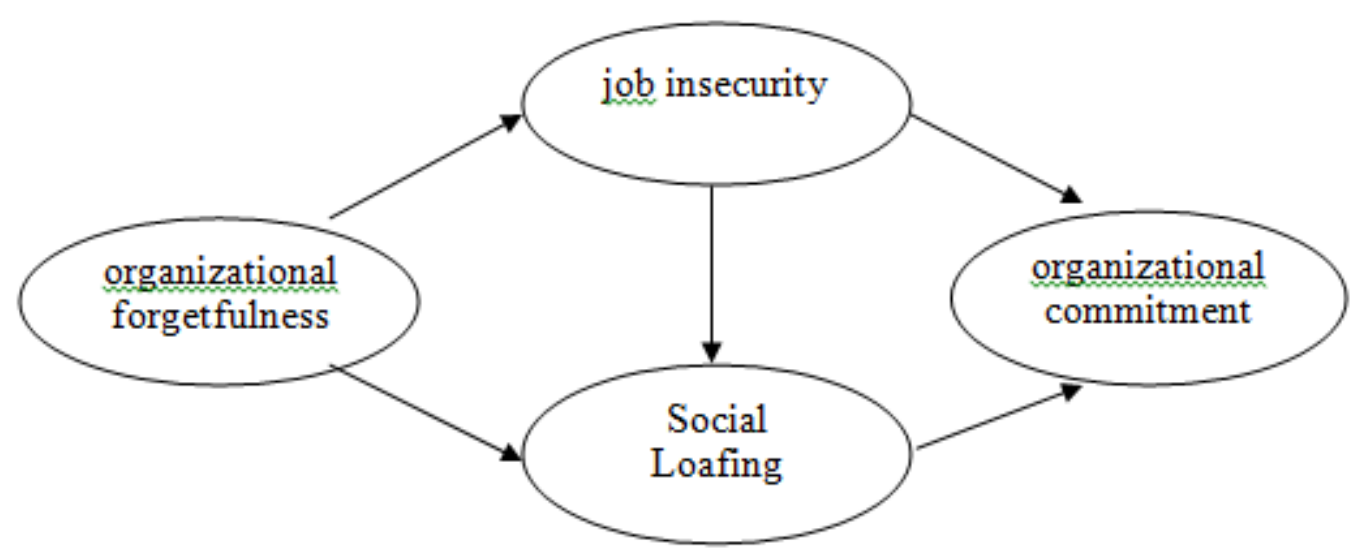

Figure 1: Conceptual model of research

\section{2-6- Research hypotheses}

In this research, according to the literature and the conceptual model of the research, the following hypotheses are presented:

1- Organizational forgetfulness has a significant effect on job insecurity.

2- Organizational forgetfulness has a significant effect on Social Loafing.

3- Job insecurity has a significant effect on Social Loafing.

4- Job insecurity has a significant effect on organizational commitment.

5- Social Loafing has a significant effect on organizational commitment.

6- Organizational forgetfulness due to job insecurity has a significant effect on organizational commitment.

7- Organizational forgetfulness due to Social Loafing has a significant effect on organizational commitment.

\section{3- Research methodology}

Methodologically, this research is a correlational research. The present study is a descriptive research based on how to obtain the required data and in terms of research classification according to their purpose. This research is applied in terms of type and descriptive-survey method.

In this research, in order to compile the basics, definitions and theoretical concepts, library resources including existing documents, books and scientific articles were used. Also, standard questionnaires were used to collect the data needed to test the research hypotheses. To measure organizational forgetfulness from Aledo Ruíz et al.'s (2017) questionnaire, to measure job insecurity from Ouyang et al.'s (2015) questionnaire, to measure social inequality from Karadal \& Saygin (2013) questionnaire and to measure 
organizational commitment variable from researchers' standard questionnaire Famous Allen and Meyer (1990), used.

The questionnaire of this research was judged by several experts and professors of human resource management and organizational behavior working in universities for content validity, and after making some corrections and obtaining approval from those professors for higher assurance and acceptability. Its face validity was distributed to about 30 questionnaires in the statistical community and at first it was not possible for the respondents to understand a number of questions and after several translations of the text and omitting a number of questions, the questionnaire had sufficient face validity and finally the case questionnaire Agreement was used as a data collection tool.

In this study, the target population is all managers and employees of government organizations in Fars province, whose number is about 43827 people. In the present study, a simple random sampling method is used to select the samples and the research questionnaire will be randomly distributed among managers and employees of government organizations in Fars province. Due to the fact that the size of the statistical population is limited and equal to 43827 people, Cochran's formula has been used to select the sample size. Therefore, the number of samples studied in this study is equal to 375 people.

\section{4- Data analysis}

In this research, structural equation modeling has been used with the help of partial least squares method and PLS software to test the hypotheses and accuracy of the model. PLS is a variance-based approach that requires fewer conditions than similar techniques to structural equations such as LISREL and AMOS. Its main advantage is that this type of modeling requires fewer samples than LISREL. It is also considered as a powerful method in situations where the number of samples and measurement items is limited and the distribution of variables can be uncertain. PLS modeling is done in two steps. In the first stage, the measurement model should be examined through validity and reliability analyzes and confirmatory factor analysis, and in the second stage, the structural model should be examined by estimating the path between variables and determining the model fit indices.

\section{4-1- Step 1: Measurement model}

The measurement model test is related to checking the validity and reliability of measuring instruments.

\section{4-1-1- Validity}

To evaluate the convergent validity, AVE (average variance extracted) and CR (composite reliability) were used. The results of this criterion for the dimensions of the six research variables are shown in Table (1). Composite reliability higher than 0.7 and mean variance higher than 0.5 are two necessary conditions for convergent validity and correlation of structures. As can be seen from Table (2), all composite reliability values are higher than 0.7 and the values of mean variance are higher than 0.5 , and this confirms that the convergent validity of the present questionnaire is acceptable. 
Table 1: Results of mean variance extracted from research structures

\begin{tabular}{|c|c|c|}
\hline Variables & CR & AVE \\
\hline organizational forgetfulness & $\mathbf{0 / 8 7 9 4}$ & $\mathbf{0 / 5 1 1 9}$ \\
\hline job insecurity & $\mathbf{0 / 8 8 3 3}$ & $\mathbf{0 / 6 0 3 4}$ \\
\hline Social Loafing & $\mathbf{0 / 8 4 8 8}$ & $\mathbf{0 / 6 1 0 2}$ \\
\hline organizational commitment & $\mathbf{0 / 8 4 9 4}$ & $\mathbf{0 / 5 3 3 5}$ \\
\hline
\end{tabular}

In the divergent validity part, the difference between the indices of one structure and the indices of other structures in the model is compared. This is calculated by comparing the AVE root of each structure with the values of the correlation coefficients between the structures. To do this, a matrix must be formed in which the principal diameter values are the square matrix of the AVE coefficients of each structure and the lower values of the principal diameter are the correlation coefficients between each structure and other structures. This matrix is shown in Table (2). As can be seen from Table (2), the AVE root of each structure is greater than the correlation coefficients of that structure with other structures, which indicates that the divergent validity of the structures is acceptable.

Table 2: Comparison matrix of AVE root with correlation coefficients of structures (divergent validity)

\begin{tabular}{|c|c|l|l|l|}
\hline & $\begin{array}{c}\text { organizational } \\
\text { forgetfulness }\end{array}$ & $\begin{array}{c}\text { job } \\
\text { insecurity }\end{array}$ & $\begin{array}{c}\text { Social } \\
\text { Loafing }\end{array}$ & $\begin{array}{c}\text { organizational } \\
\text { commitment }\end{array}$ \\
\hline organizational forgetfulness & $0 / 715$ & & & \\
\hline job insecurity & $0 / 485$ & $0 / 776$ & & \\
\hline Social Loafing & $0 / 603$ & $0 / 369$ & $0 / 781$ & \\
\hline organizational commitment & $0 / 544$ & $0 / 547$ & $0 / 469$ & $0 / 730$ \\
\hline
\end{tabular}

\section{4-1-2- Reliability}

In addition to Cronbach's alpha coefficient, which is presented in Table 3 and confirms the appropriate reliability of the questionnaire, the PLS method was used to evaluate the reliability of the questionnaire. The PLS method uses index reliability. The reliability of the index is also measured by measuring the factor loads by calculating the correlation value of the indices of a structure with that structure, which if this value is equal to or greater than 0.6 , confirms that the reliability in The case for that is an acceptable measurement model. However, if the value of the factor load between a question and the relevant dimension is less than 0.6, that question can be removed from the model and subsequent analyzes. As can be seen in Figure (2), all values of factor loads between structures and questions are greater than 0.6, which shows a high correlation. 
Table 3: Cronbach's alpha coefficient

\begin{tabular}{|c|c|}
\hline Variables & Cronbach's alpha \\
\hline organizational forgetfulness & $\mathbf{0 / 8 3 9 6}$ \\
\hline job insecurity & $\mathbf{0 / 8 3 4 1}$ \\
\hline Social Loafing & $\mathbf{0 / 9 4 3 3}$ \\
\hline organizational commitment & $\mathbf{0 / 7 7 9 9}$ \\
\hline
\end{tabular}

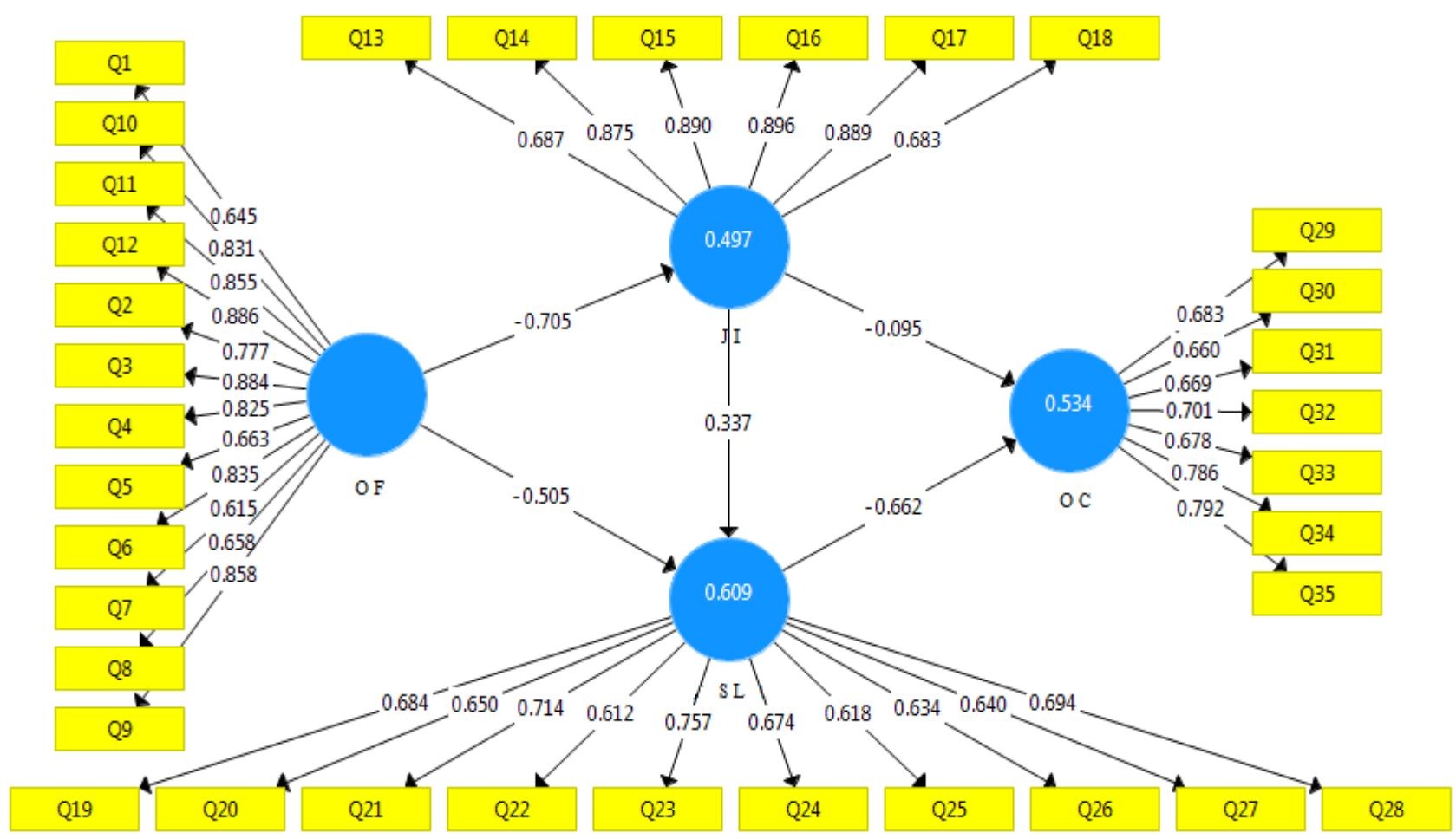

Figure 2: Software output - test model of the research (path coefficients and operating loads)

\section{4-2- Second stage: structural model and testing of hypotheses}

Structural model test, which is related to testing research hypotheses and the effect of hidden variables on each other. To confirm the research hypotheses, the Bootstrapping command of Smart PLS software was used, which shows the output of t-coefficients (Figure 3). When the values of $t$ in the range are more than +1.96 and less than -1.96 , it indicates the significance of the relevant parameter and subsequently confirms the research hypotheses. 


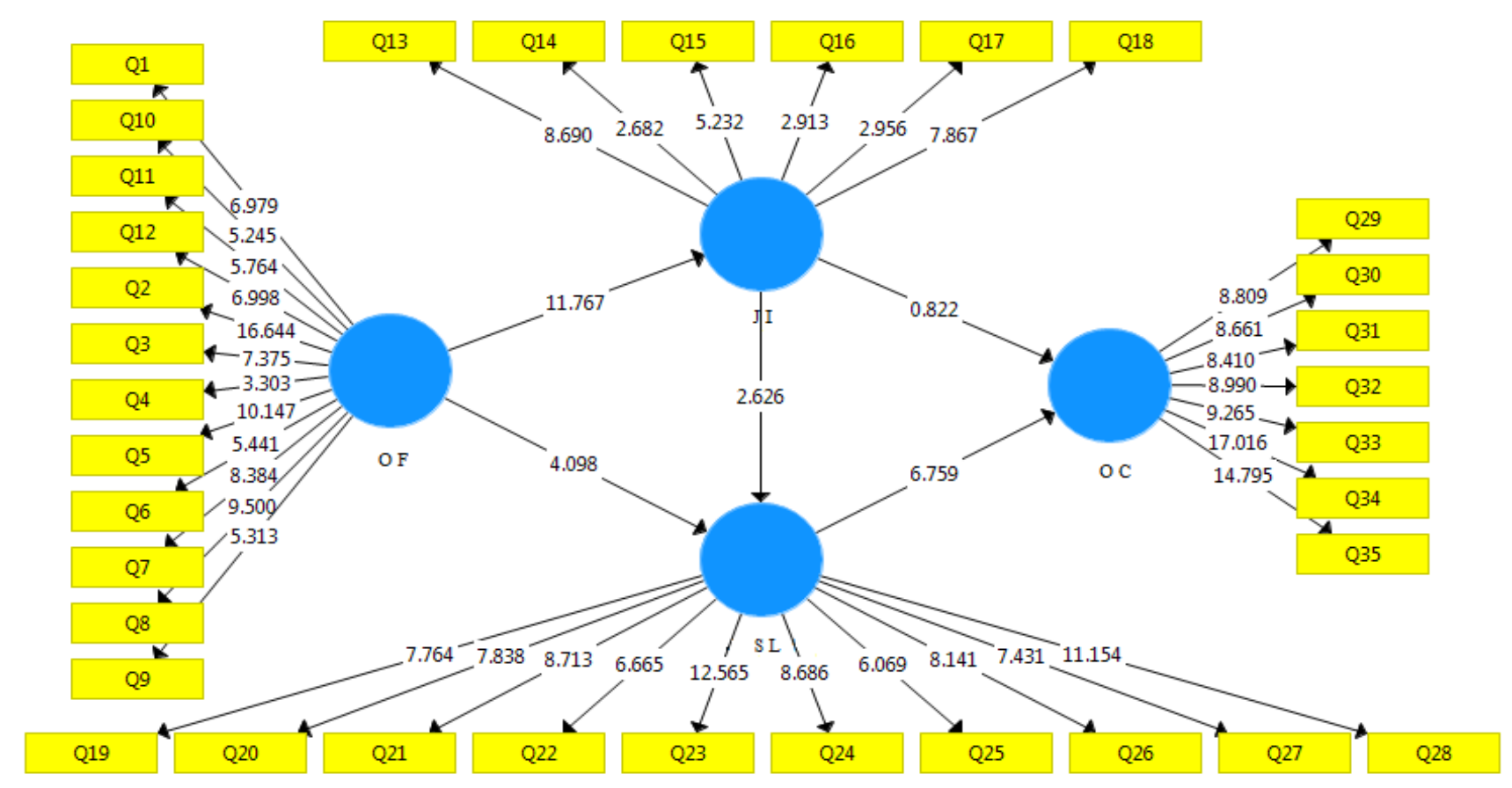

Figure 3: Software output - coefficients $t$

\section{4-3- Methods of evaluating shaping models}

One way to evaluate shaping models is the coefficient of determination (R2). The coefficient of determination (R2) examines what percentage of the variance of a dependent variable is explained by the independent variable (s). Therefore, it is natural that this value is equal to zero for the independent variable and more than zero for the dependent variable. The higher this rate, the higher the coefficient of effect of the independent variables on the dependent. Based on the coefficient of determination of the model, it can be said that the organizational forgetfulness variable could explain 0.497 of the variance of the job insecurity variable. Also, the variables of organizational forgetfulness and job insecurity together could explain 0.609 of the variance of the social void variable. The variables of job insecurity and social idleness together could explain 0.534 of the variance of the variable of organizational commitment; Researchers have introduced three values of $0.19,0.33$ and 0.67 as the criterion values for weak, medium and strong values of R2. Based on this, it can be concluded that the model has a high predictability's residual value is related to forecast error and can include other factors affecting job insecurity, social idleness and organizational commitment. 


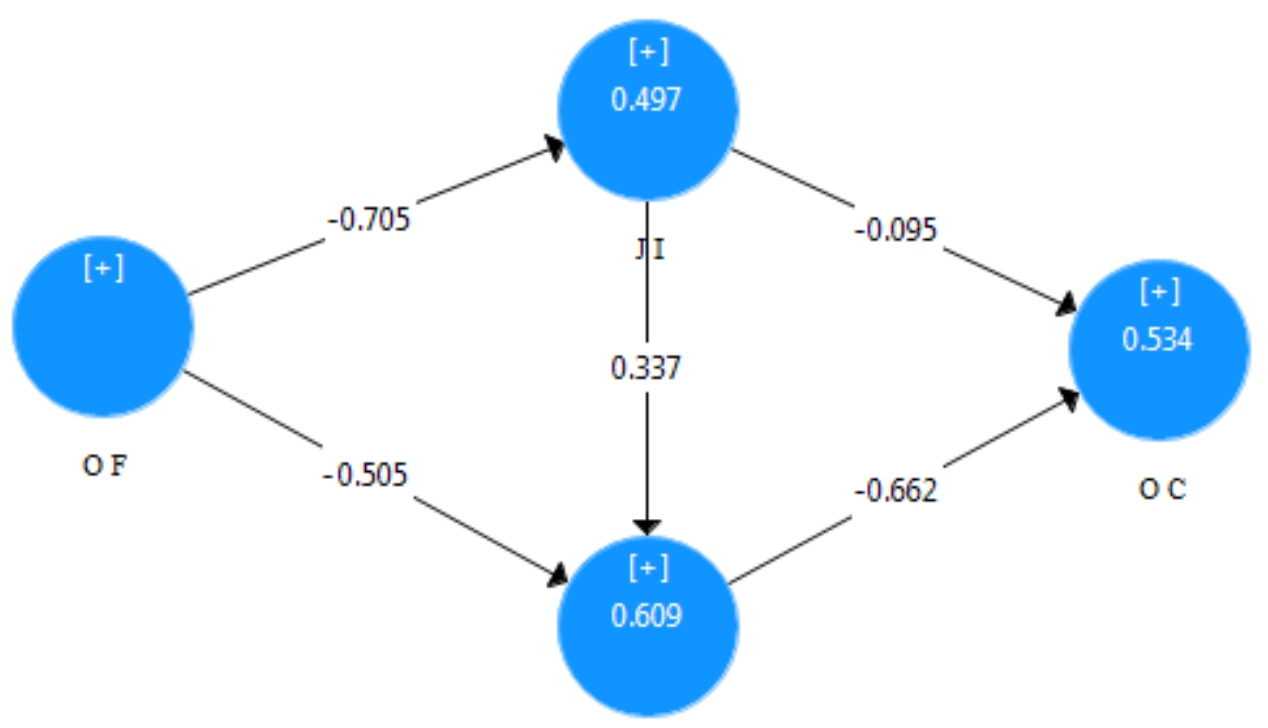

S L

Figure 4: Evaluation of shaper measurement models

\section{4-4- Answer to research hypotheses}

According to the results obtained from the path coefficient and t-statistic, organizational forgetfulness has a negative and significant effect on job insecurity and social idleness. The results also show that job insecurity has a positive and significant effect on social inequality. The results confirm the effect of social void on organizational commitment and the effect of organizational forgetfulness on organizational commitment due to the mediation role of social void but the effect of job insecurity on organizational commitment and the effect of organizational forgetfulness on organizational commitment due to the role of mediation do not confirm job insecurity. 
Table 4: Direct effects, $t$-statistic and the result of research hypotheses

\begin{tabular}{|c|c|c|c|c|}
\hline hypothesis & $\begin{array}{c}\text { Standardized path } \\
\text { coefficient } \beta\end{array}$ & statistics T & Meaningful & $\begin{array}{c}\text { No rejection or } \\
\text { Reject }\end{array}$ \\
\hline organizational forgetfulness $\rightarrow$ job insecurity & -0.705 & 11.767 & Sig<0.05 & approved \\
\hline organizational forgetfulness $\rightarrow$ Social Loafing & -0.505 & 4.098 & Sig<0.05 & Sig<0.05 \\
\hline job insecurity $\rightarrow$ Social Loafing & 0.337 & 2.626 & Sig $>0.05$ & Rejection \\
\hline job insecurity $\rightarrow$ organizational commitment & -0.095 & 0.822 & Sig<0.05 & approved \\
\hline Social Loafing $\rightarrow$ organizational commitment & -0.662 & 6.759 & Sig $>0.05$ & Rejection \\
\hline $\begin{array}{c}\text { organizational forgetfulness } \rightarrow \text { Organizational commitment } \\
\text { with respect to the mediating role of job insecurity }\end{array}$ & 0.067 & $11.767,0.822$ & Sig<0.05 & approved \\
\hline $\begin{array}{c}\text { organizational forgetfulness } \rightarrow \text { Organizational commitment } \\
\text { with respect to the mediating role of Social Loafing }\end{array}$ & 0.334 & $6.759,4.098$ & \\
\hline
\end{tabular}

\section{5- Conclusions and suggestions}

The purpose of this study is the mediating role of social idleness and job insecurity in the effect of organizational forgetfulness on organizational commitment in government organizations in Fars province. This study refers to organizational forgetfulness as a process to create room for new concepts. In today's turbulent changing environment, achieving higher levels of performance requires identifying, interpreting, and acting on ambiguous cues that arise from outdated knowledge structures. Therefore, the perspective of organizational forgetfulness is important for the discussion about the importance of organizational forgetfulness in achieving goals.

The findings of this study validate previous research that argued that in order to increase organizational performance, the primary knowledge that needs to be updated is employee knowledge (Kapada et al., 2012). For example, not only by updating the right customer and client relationships and priorities, but also through other resources such as identifying new approaches or threats and opportunities in emerging markets, organizations find new solutions for current and potential clients. Will provide.

Findings show that creating the ground for organizational forgetfulness has a significant effect on job insecurity and social idleness. One possible explanation is that organizational forgetfulness allows individuals to adapt their mental models and the nature of the hypotheses they share to the current workplace culture, and helps employees more effectively solve problems with a vision. Examine problems and unforeseen circumstances. If employees are able to develop their individual skills through reflective exploration of past, present and future decisions or through conversations with their managers, they can change their behaviors and thoughts and create new knowledge. This is in line with the fact that if managers encourage employees to transfer their knowledge to other employees and use their knowledge to create new ideas and solutions, it will make the organization benefit from the benefits of reducing idleness and the disadvantages. Get rid of job insecurity. 
As the results show, job insecurity has a significant effect on social inactivity of employees. Because a large part of workers' perception of job insecurity or the risk and consequences of losing a job is due to fear of being fired due to lack of need and dire labor market conditions. Although many workers may be fired for lack of need, it is sometimes observed that this also happens in the era of profitability, where the lack of timely and proper legal protections is challenged. So in addition to dismissal due to lack of need, lack of legal protections and inefficient laws can also be the main reasons for job insecurity in the workplace and even the effects of the dismissal period on workers who have kept their jobs. Therefore, in government organizations in Fars province, by creating a safe environment for employees who feel they have a sustainable job and eliminate the fear of dismissal in them, job insecurity can be reduced and thus their social idleness can be reduced.

The results showed that social idleness leads to a decrease in organizational commitment in employees, so managers of government organizations in Fars province should reduce idle behavior in employees by involving employees in organizational activities and placing them in the team activities of the organization. People with less idleness in the organization will have fewer problems such as absenteeism, resignation and dismissal. In new organizational environments, often described in terms such as complexity, turbulence, speed, and rapid change, managers must motivate employees to believe in the goals and values of the organization, to make significant efforts, and to have a strong desire to continue. Commit to membership in the organization, which will reduce social void.

\section{References}

Aledo Ruíz, M.D., Gutiérrez, J. O., Martínez-Caro, E., Cegarra-Navarro, J.G . (2017). Linking an unlearning context with firm performance through human capital. European Research on Management and Business Economics.2017; 23.16-22.

Allen, M., Wat, K. (1991). the relationship between communications affect, job alternative and voluntary turnover intentions, journal citation: southern - communication -journal, vol41, n3.

Allen, D. G., Shore, L. M., \& Griffeth, R. W. (2003). The Role of Perceived Organizational Support and Supportive Human Resource Practices in the Turnover Process. Journal of Management, 29(1), 99-118.

Ang, Soon., \& Dyne Linn Van., and Begley Thomas.(2003), "The Employment Relationship of Foreign Workers Versus Local Employees: A Field Study of Organizational Justice, Job Satisfaction, Performance and OCB". Journal of Organizational Behavior. N 24, 561-583.

Artz, B, Kaya, I. (2015). The impact of Job Security on Job Satisfaction in Economic Contractions Versus Expansions, discussions: https://www.researchgate.net/publication/261634552.

Azmi, F. (2008). Mapping the learn-unlearn-relearn model: Imperatives for strategic management. European Business Review.2008; 20(3), 240-259.

Becker, K. (2010). Facilitating unlearning during implementation of new technology. Journal of Organizational Change Management.2010; 23(3), 251-268.

Birasnav, M.(2014). Knowledge management and organizational performance in the service industry: The role of transformational leadership beyond the effects of transactional leadership. Journal of Business Research.2014; 67(8), 1622-1629. 
Blaga, P., Jozsef, B. (2014). Human resources, quality circles and innovation. Procedia - Social and Behavioral Sciences, 1458-1462.

Burke, R. Y. (1991). Job Insecurity in Stock 13 Rokers. Journal of Managerial Psycology. Vol. 6, No. 5, PP. 10-16.

Cegarra, J. G., Wensley, A., \& Sanchez, M. T. (2014). A conceptual framework for unlearning in a homecare setting. Knowledge Management Research and Practice.2014;12(4), 375-386.

Cepeda, G., Cegarra, J. G., Martinez, E., \& Eldridge, S.(2011). How can managers in the hospital in the home units help to balance technology and physician-patient knowledge?? International Journal for Quality in Health Care.2011; 23(5), 600-609.

Chang, C-M., Hsieh, H.H., Huang, H.C., Lin, Y.C. (2017). The relationships among Personality Trait, Job Stress and Career Development Satisfaction of Lifeguards in Taiwan, International Journal of Organizational Innovation, 10(2): 188-204.

Cheng, Y., Huang, H.-Y., Li, P.-R., \& Hsu, J.-H. (2011). Employment insecurity, workplace justice and employees' burnout in Taiwanese employees: A validation study. International Journal of Behavioral Medicine, 18(4), 391-401.

Cho, V. \& Huang, X. (2012). Professional commitment, organizational commitment, and the intention to leave for professional advancement: An empirical study on IT professionals. Information Technology \& People. 25: 31-54.

Cullinan, C., Bline, D., Farrar, R. \& Lowe, D. (2008). Organization - Harm vs. Organization - Gain Ethical Issues: An Exploratory Examination of the Effects of Organizational Commitment, Journal of Business Ethics, 80: 225 235 .

Durst, S., \&Edvardsson, I. (2012). Knowledge management in SMEs: A literature review. Journal of Knowledge Management.2012; 16, 879-903.

Fornell, C. (2000). Customer asset management, capital efficiency, and shareholder value: Performance measurement, past, present and future. In Conferenciaen la Universidad de Cambridge.2000; Available fromhttp://www.cranfield.ac.uk/som/cbp/claeskeynote.htm

George, J. M., (1992). Extrinsic and intrinsic origins of perceived social loafing in organizations. Academy of Management Journal, 35, 191-202.

Greenhalgh, L., \& Rosenblatt, Z. (1984). Job insecurity: Toward conceptual clarity. Academy of Management Review, 9(3), 438-448.

Hair, J.F., Jr., Black, W.C., Babin, B.J., Anderson, R.E. \& Tatham, R.L. (2010). Multivariate data analysis. New Jersy: Pearson Education.

Howells, J., \&Scholderer, J. (2015). Forget unlearning? How an empirically unwarranted concept from psychology was imported to flourish in management and organization studies'. Management Learning.2015; 1-37 (accepted for publication).

Hulland. (1999). Use of partial least Science, Environment, Engineering and Technology Griffith University.

Karadal, H., \& Saygin, M. (2013). An Investigation of the Relationship between Social Loafing and Organizational Citizenship Behavior, International Strategic Management Conference, Procedia - Social and Behavioral Sciences 99 ( 2013 ) $206-215$.

Liljander, V., Polsa, P., \& van Riel, A. (2009). Modelling consumer responses to an apparel store brand: Store image as a risk reducer. Journal of Retailing and Consumer Services , 16, 281-290.

Loi, R., Lam, L. W., \& Chan, K. W. (2012). Coping with job insecurity: The role of procedural justice, ethical leadership and power distance orientation. Journal of Business Ethics, 108(3), 361-372.

Lu, H., Zhao, Y., While, A. (2019). Job Satisfaction among Hospital Nurse: a Literature Review. International Journal of Nursing Studies. 94: 21-31. 
MacIntosh, E.W, \& Doherty. A,. (2010). The influence of organizational culture on job satisfaction and intention to leave. Sport Management Review, 106-117.

Organ, D.W. (1988). Organizational citizenship behavior: The good soldier syndrome. Lexington, MA: Lexington Books.

Ouyang, Zh., Sang, J., Li, P., Peng, J. (2015). Organizational justice and job insecurity as mediators of the effect of emotional intelligence on job satisfaction: A study from China. Personality and Individual Differences. 76 (2015). $147-152$.

Podsakoff, P. M. , MacKenzie, S. B. , Paine, J. B. , \& Bachrach, D. G. (2000). "Organizational Citizenship Behaviors: A Critical Review of the Theoretical and Empirical Literature and Suggestions For Future Research". Journal of Management, 26, 513-563.

Rivard \& Huff. (1988). Factors of success for End-User computing. Communications of the ACM 31:5, May, pp , $552-561$

Roskies, E. \& Louis, G. (1990). Job Security in Managers. Antecedents and Conseguences. Journal of Organization Behavior. Vol. 11, No. 3, PP. 345-359.

Tsang, E., \& Zahra, S.(2008). Organizational unlearning? Human Relations.2008; 61(10),1435-1462.

Uike , H. E, (2006). Investigating The Role Of Personality And Justice Perceptions On Social Loafing, A Thesis Submitted To The Graduate School Of Social Sciences Of Middle East Technical University.

Uike, H.E. and Bilgic, R., (2011). Investigating the Role of the Big Five on the Social Loafing of Information Technology Workers, International Journal of Selection and Assessment, Volume 19 Number 3, pp.301-312.

Wang, X. Y., Lu, Y. Q., Zhao, Y. X., Gong, S. L., \& Bai, L. (2013). Organizational unlearning, organizational flexibility and innovation capability: An empirical study of SMEs in China. International Journal of Technology Management.2013; 61(2), 132-155.

Wensley, A. K., \&Cegarra, J. G.(2015). Overcoming knowledge loss through the utilization of an unlearning context. Journal of Business Research.2015; 68(7), 1563-1569.

Westover, J. H. Westover, A. R. \& Westover, L. (2010), "Enhancing long-term worker productivity and performance, Journal of Productivity and Performance Management, 59(4): 372-387.

Zhao, Y., Lu, Y., \& Wang, X. (2013). Organizational unlearning and organizational relearning: A dynamic process of knowledge management. Journal of Knowledge Management.2013; 17(6), 902-912. 